Indonesian Journal of Cardiology

Indonesian J Cardiol 202 I:42:86-93

pISSN: 0I 26-3773 / elSSN: 2620-4762 doi: $10.30701 /$ ijc. 1149

\title{
Cryptogenic Stroke: \\ A Challenge in Diagnosis and Management
}

\author{
Sidhi Laksono, ${ }^{1,2}$ Budhi Setianto, ${ }^{3}$ I Nyoman Wiryawan, ${ }^{4}$ \\ Gea Panindhita, 2,5 Reynaldo Halomoan ${ }^{6}$
}

' Department of cardiology and vascular medicine, RSUD Pasar Rebo, East Jakarta, Indonesia ${ }^{2}$ Faculty of medicine, Universitas Muhammadiyah Prof Dr Hamka, Tangerang, Indonesia

${ }^{3}$ Department of cardiology and vascular medicine, National Heart Centre of Harapan Kita, Faculty of medicine, Universitas Indonesia ${ }^{4}$ Department of cardiology and vascular medicine, RSUP Sanglah, Faculty of medicine of Universitas Udayana, Bali, Indonesia

${ }^{5}$ Department of neurology, RSPI

Bintaro, Tangerang, Indonesia

${ }^{6}$ Faculty of Medicine of Universitas

Katolik Indonesia Atma Jaya, Jakarta.

Correspondence:

Sidhi Laksono.

Faculty of Medicine, Universitas Muhammadiyah Prof. Dr. Hamka, Kota Tangerang, Banten

Email: sidhilaksono@uhamka.ac.id

\begin{abstract}
Ischemic stroke is responsible for $\mathbf{8 5 \%}$ of all stroke globally. However, the etiology of around a quarter of ischemic stroke are undetermined, this is called cryptogenic stroke. This kind of stroke affects younger population. Several mechanism are associated with the incidence of cryptogenic stroke such as paroxysmal atrial fibrillation, patent foramen ovale, atherosclerosis, and atrial cardiopathy. Despite many advanced knowledge on stroke generally, cryptogenic stroke is still a challenge in clinical settings. To understand more about cryptogenic stroke, a new term of embolic strokes of undetermined source (ESUS) is proposed and may need a specific workup. Specific workup aims to detect any silent risk factors and also to evaluate the cardiac structure. The term of ESUS also leads to the understanding that cryptogenic stroke is highly related to embolic mechanism and anticoagulation administration might benefit the patients. However, the result of several recent studies showed that anticoagulant was not superior to antiplatelet, and antiplatelet is still the preferred treatment. Studies on patent foramen ovale closure also shows different result, but the majority of the trials showed benefit of patent foramen ovale closure in reducing the risk of stroke recurrence.
\end{abstract}

(Indonesian J Cardiol. 2021;42:86-93)

Keywords: cryptogenic stroke, diagnostic workup, management strategy, mechanism. 


\section{Introduction and Definition}

S troke remains a serious condition due to impairment of cerebral perfusion and remain a global burden. Stroke can be categorized as ischemic and hemorrhagic. Ischemic stroke accounts for $85 \%$ of all stroke incidence. ${ }^{1}$ However, despite the advanced knowledge on ischemic stroke, there is a type of ischemic stroke which the etiology can not be identified. This type of stroke is known as cryptogenic stroke. However, the term cryptogenic stroke is lack of specificity. Trial of Org 10172 in Acute Stroke Treatment (TOAST) is one of several classifications for stroke. TOAST defined cryptogenic stroke as a stroke which the cause is undetermined (not related to large artery atherosclerosis, cardioembolism, small vessel disease), the presence of two or more possible causes, or due to incomplete evaluation of the etiology. ${ }^{2}$ Another classification of stroke, Causative Classification of Stroke System (CCS), divides stroke into 5 subtypes: supra-aortic large artery atherosclerosis, cardioembolism, small artery occlusion, other uncommon causes, and also undetermined causes. ${ }^{3}$ The CCS classifies cryptogenic stroke as undetermined causes (this group is divided into cryptogenic embolism, other cryptogenic, incomplete evaluation, and unclassified). ${ }^{4}$ Lastly, ASCOD classification classifies stroke based on the etiology. ASCOD stands for atherosclerosis, small vessel disease, cardiac, other, and dissection.5 Cryptogenic stroke is included into 'other' because ASCOD classification has no other categories that can describe cryptogenic stroke. These 3 classification have a different perspective on defining cryptogenic stroke. However, there are similarities in that the diagnosis of cryptogenic stroke is a diagnosis of exclusion, which other well-known etiologies have been excluded. The differences between these three classifications raises concern about the establishment of cryptogenic stroke diagnosis because both patients who underwent a minimal or limited diagnostic testing and patients who had an extensive testing then had normal evaluation will be classified as cryptogenic stroke.

Cryptogenic stroke is very related to embolic mechanism. Therefore, a new term to define cryptogenic stroke has been described. Cyptogenic Stroke/ESUS International Working Group has offered this new term called embolic strokes of undetermined source
(ESUS). ${ }^{6}$ This new term sought to define cryptogenic stroke clearly, based on the diagnostic criteria: a nonlacunar stroke without evidence of more than 50\% proximal arterial stenosis (intra- and extracranial) or cardioembolic sources (paroxysmal atrial fibrillation, atrial flutter, thrombus, tumor, valve disease). Patients need to undergo several evaluation using brain computed tomography (CT) or magnetic resonance imaging (MRI), electrocardiography (ECG), echocardiography, Holter monitoring. ${ }^{6}$ Apart from its new term of ESUS, management using anticoagulants such as dabigatran and rivaroxaban showed no benefit compared to antiplatelet in reducing stroke of undetermined source reccurence. ${ }^{7,8}$ The purpose of this review is to discuss recent findings related to the evolving concept, diagnosis and management of cryptogenic stroke.

\section{Epidemiology}

Generally, the incidence of cryptogenic stroke is around $10-40 \%$ of ischemic stroke events. This percentage is getting lower through the years as a more advanced diagnostic modalities were done for evaluation. ${ }^{9-11}$ In United States, cryptogenic stroke affects around 25\% of all patients with ischemic stroke (180.000 people) each year. ${ }^{6}$ The incidence of cryptogenic stroke is higher in younger population. Presence of vascular risk factors also decrease the likelihood of cryptogenic stroke. A stroke registry in Helsinki showed a decreased incidence of undetermined source stroke from $>60 \%$ to around $25 \%$ in patients aged $15-19$ years old and $45-49$ years old, respectively. ${ }^{12}$

\section{Potential Mechanism and Diagnostic Workup}

\section{Atrial Fibrillation}

Atrial fibrillation (AF) is a well-known etiology for stroke. However, paroxysmal and asymptomatic AF make it hard for clinician to detect the presence of $\mathrm{AF}$ in patients with cryptogenic stroke. ECG evaluation during the first 3 days of stroke onset and 24-hour Holter monitoring should be done as the first evaluation strategy. However, a prolonged heart rhythm monitoring might be needed after an event of cryptogenic stroke to prevent the stroke recurrence. There are 2 trials that studied about prolonged cardiac monitoring gave a beneficial impact in detect AF. EMBRACE trial, a 
multi-center study, divided patients with cryptogenic stroke or transient ischemic attack (TIA) into two groups, usual care using 1-day Holter monitoring and 30-day outpatient monitoring. The primary outcome was 30 seconds of AF. This trial showed that detection of AF was higher in patient who had 30-day cardiac monitoring compared to 1-day monitoring, $16.1 \%$ and $3.2 \%$ respectively. ${ }^{13}$ The other trial, CRYSTAL-AF, compared patients with cryptogenic stroke or TIA with usual care (ECG and inpatient monitoring) vs. group of patients who underwent a longer cardiac monitoring using insertable cardiac monitor (ICM). The primary outcome was first detection of $\mathrm{AF}>30$ seconds within 6 months. The result of this study showed that detection of AF at 6 months was higher in ICM patients versus usual care group $(8.9 \%$ vs $1.4 \%$, hazard ratio [HR] 6.4; 95\% confidence interval $[\mathrm{CI}], \mathrm{p}<0.001) .{ }^{14}$ These results show that long-term rhythm monitoring in outpatient setting is beneficial in detecting AF, especially in patients after first cryptogenic stroke event. Another prospective study by Jofrida et al. also suggested that long-term rhythm monitoring was able to detect as many as $46 \%$ asymptomatic atrial fibrillation in patients with cryptogenic stroke with risk factors for AF but no history of arrhythmia. ${ }^{15}$ This study showed a higher AF detection compared to EMBRACE and CRYSTALAF study. This might be due to the difference in the duration of AF being monitored ( $>5$ minutes vs $>30$ seconds). To date, there is no consensus on the optimal AF duration that should be monitored to be clinically significant.

\section{Patent Foramen Ovale}

Patent foramen ovale is a congenital abnormality of the heart that is related to an occurrence of cryptogenic stroke. Patent foramen ovale is a potential source of emboli due to thrombus formation. Paradoxical embolism may also occur in patent foramen ovale. This happens when thrombus originating from venous system circulate through systemic circulation to the arterial system through the presence of right-to-left shunt. ${ }^{16}$ The prevalence of patent foramen ovale is higher in populations with cryptogenic stroke than normal subjects. It is also suggested to be an important risk factor of cryptogenic stroke, especially in younger population. ${ }^{17}$ The prevalence of patent foramen ovale in patients with cryptogenic stroke is around $40 \%$.
The probability of finding patent foramen ovale in cryptogenic stroke is almost 3 times higher compared to control subjects (stroke with established etiology). ${ }^{18} \mathrm{To}$ diagnose the presence of patent foramen ovale, patients will be examined using transthoracic echocardiogram (TTE) with high-specificity for patent foramen ovale. During examination, patients will be asked to perform valsalva maneuver and we can find an agitated saline bubbles to the left atrium within 3 cardiac cycles. ${ }^{19,20}$ TTE detects less patent foramen ovale compared to transoesophagal echocardiogram (TEE). TEE is also the preferred method because it is better than TTE in evaluating the morphology of the shunt. ${ }^{16}$ Suspicion of patent foramen ovale in patients with negative bubble study from TTE examination might lead to additional examination using TEE. However, examination using TEE makes it difficult for the patient to perform valsalva maneuver. If patients are not eligible to undergo TEE and TTE examination result is not conclusive, transcranial Doppler ultrasonography might be used. ${ }^{21}$ Though patent foramen ovale is quite common found in stroke events, it is still a challenge to determine wether patent foramen ovale is incidental or stroke-related. To overcome this challenge, a tool consists of 6 variables related to patent foramen ovale can be used to determine the probability of patent foramen ovale to be associated with stroke. The Risk of Paradoxical Embolism (ROPE) consist of variables about the presence of risk factors and age. Patients with ROPE scores 7-10 have high likelihood of patent foramen ovale-related stroke. ${ }^{22}$

\section{Atrial Cardiopathy}

The term of atrial cardiopathy arises because there is conflicting findings on subclinical AF as an embolic source. Although AF is highly associated with thrombus formation, a study showed no association between subclinical AF and embolic events. ${ }^{23}$ Atrial cardiopathy can be diagnosed based on the ECG appearance, imaging, and also biomarker levels. ECG examination will show $\mathrm{P}$ wave terminal force in $\mathrm{V} 1$. The biomarker measured to diagnose atrial cardiopathy is NT-proBNP (N-terminal pro-B-type natriuretic peptide) ${ }^{24}$ Atrial fibrosis increases the risk of stroke. In a study using magnetic resonance imaging (MRI) to evaluate atrial structure, atrial fibrosis was found more prevalent in group of patients with cryptogenic stroke. In this study, percentage of atrial fibrosis was comparable in patients 


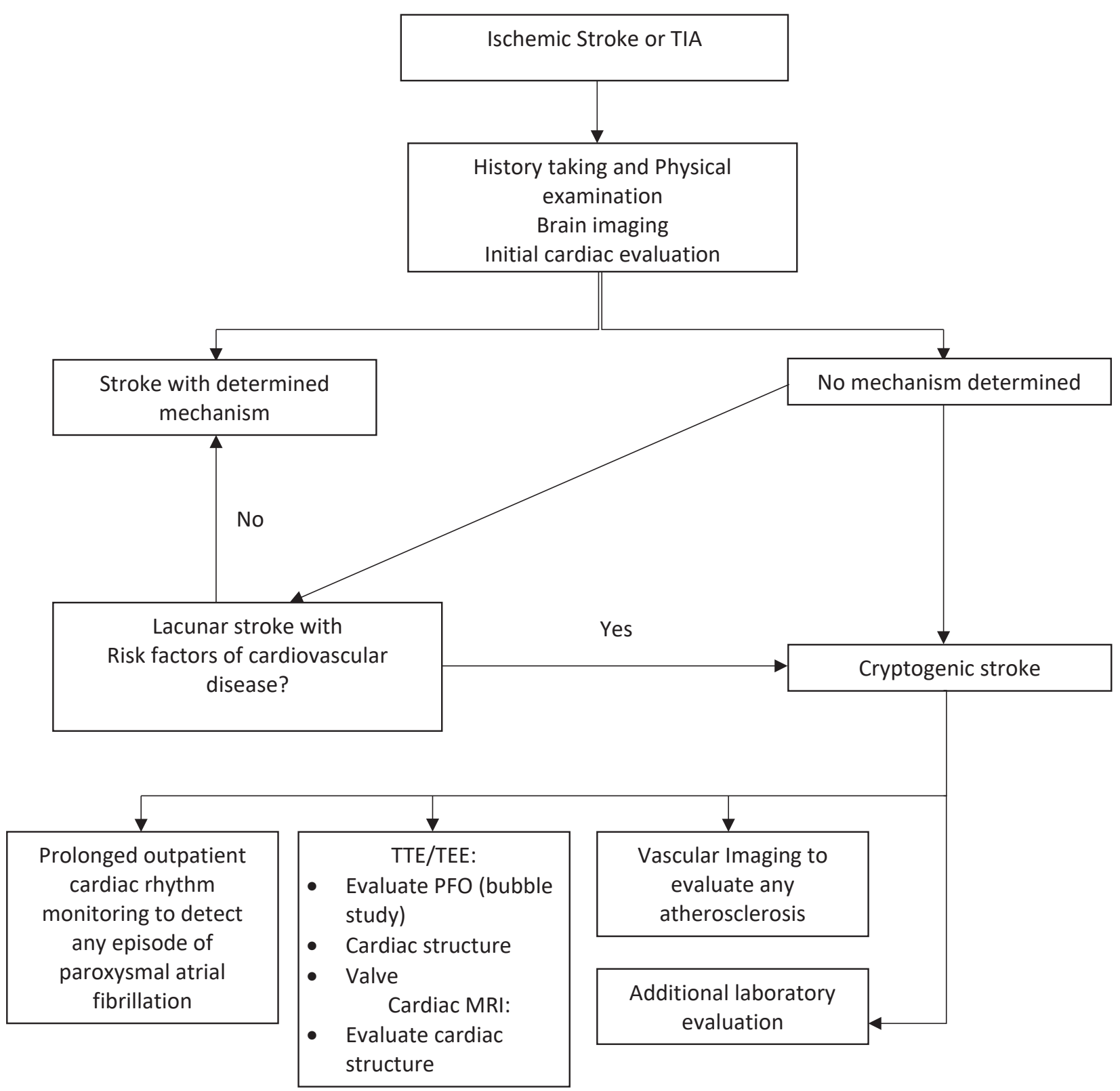

Figure 1. Proposed diagnostic algorithm for cryptogenic stroke.

with AF and undetermined source of stroke. ${ }^{25}$

\section{Atherosclerosis}

Atherosclerotic plaque is a potential etiology for ischemic stroke. In cryptogenic stroke, substenotic atherosclerotic plaque also has a role due to plaque rupture and artery-to-artery embolization. In a study by Gupta et al., it was showed that in $22 \%$ of patients with cryptogenic stroke, evidence of intraplaque haemorrhage was found and became the underlying mechanism of cryptogenic stroke. This study used magnetic resonance angiography (MRA) to evaluate the plaque. The plaque was also found ipsilateral to the infarct. ${ }^{26}$ Aortic arch atherosclerosis (AAA) is suggested to be a risk factor for cryptogenic stroke. A mobile complex plaque with size of $4 \mathrm{~mm}$ increases the risk of embolism. ${ }^{27,28}$ Detail evaluation of AAA is essential to determine the extent 
Indonesian Journal of Cardiology

Table 1. Trials Comparing patent foramen ovale Closure and Medical therapy.

\begin{tabular}{|c|c|c|c|c|}
\hline Name & Result & Value & Result & Result \\
\hline CLOSURE $^{31}$ & $\begin{array}{l}\text { Percutaneous } \\
\text { closure device }\end{array}$ & $\begin{array}{l}\text { Aspirin, warfarin, } \\
\text { or both }\end{array}$ & $\begin{array}{c}\text { Stroke or TIA in } 2 \\
\text { years }\end{array}$ & $\begin{array}{l}\text { No benefit of patent foramen ovale } \\
\text { closure, stroke or TIA recurrence is } \\
5.5 \% \text { vs } 6.8 \% \text { in patent foramen ovale } \\
\text { closure group and medical therapy } \\
\text { group respectively }(\mathrm{p}=0.37)\end{array}$ \\
\hline $\mathrm{PC}^{32}$ & $\begin{array}{l}\text { Percutaneous } \\
\text { closure device }\end{array}$ & Any antithrombotic & $\begin{array}{c}\text { Stroke, TIA, } \\
\text { peripheral } \\
\text { embolism, or death }\end{array}$ & $\begin{array}{l}\text { No benefit of closure compared to } \\
\text { medical treatment. }\end{array}$ \\
\hline $\begin{array}{l}\text { GORE- } \\
\text { REDUCE } 33\end{array}$ & $\begin{array}{l}\text { Percutaneous } \\
\text { closure }\end{array}$ & antiplatelet & stroke recurrence & $\begin{array}{l}\text { Stroke recurrence in patent foramen } \\
\text { ovale vs medical therapy: } 1.4 \% \text { vs } 5.5 \% \\
\qquad(\mathrm{p}<0.04)\end{array}$ \\
\hline RESPECT $^{34}$ & $\begin{array}{l}\text { Percutaneous } \\
\text { closure }\end{array}$ & $\begin{array}{l}\text { Aspirin' clopidogrel, } \\
\text { warfarin' or aspirin/ } \\
\text { dipyiridamole }\end{array}$ & Stroke or death & $\begin{array}{l}\text { Stroke recurrence in patent foramen } \\
\text { ovale vs medical therapy: } 3.6 \% \text { vs } 5.8 \% \\
(\mathrm{p}=0.046)\end{array}$ \\
\hline CLOSE $^{35}$ & $\begin{array}{l}\text { Percutaneous } \\
\text { closure }\end{array}$ & $\begin{array}{c}\text { Antiplatelet or } \\
\text { anticoagulant }\end{array}$ & Stroke recurrence & $\begin{array}{l}\text { No patients in patent foramen ovale } \\
\text { closure group had stroke recurrence. } \\
14 \text { patients in antiplatelet group had } \\
\text { recurrence of stroke }\end{array}$ \\
\hline $\begin{array}{l}\text { DEFENSE- } \\
\text { patent foramen } \\
\text { ovale }^{36}\end{array}$ & $\begin{array}{l}\text { Percutaneous } \\
\text { closure }\end{array}$ & $\begin{array}{c}\text { Any antithrombotic } \\
\text { agent }\end{array}$ & $\begin{array}{l}\text { Stroke, death, or } \\
\text { major bleeding. }\end{array}$ & $\begin{array}{l}\text { No patients reached the primary } \\
\text { endpoint in patent foramen ovale } \\
\text { closure group compared to medical } \\
\text { therapy group }(12.9 \%)\end{array}$ \\
\hline
\end{tabular}

of the lesion. Examination using TEE can give a detail information on morphology of the plaque and also the location. ${ }^{29}$ A less invasive yet reliable modality such as computerized tomography angiography (CTA) or MRI can also be done, especially, these modalities give additional information on the other parts of aorta (descending and abdominal aorta). ${ }^{30}$

\section{Treatment}

Management of stroke is essential to prevent recurrence. This includes controlling the risk factor. Antithrombotic therapy using antiplatelet has been and still the treatment of choice for cryptogenic stroke patients. Given that cryptogenic stroke is associated with embolic mechanism, administration of anticoagulant may be beneficial. Several studies have studied the comparison between some anticoagulant and antiplatelet in managing cryptogenic stroke. NAVIGATE-ESUS and RESPECT-ESUS are two trials that compared the use of novel oral anticoagulant to antiplatelet. ${ }^{7,8}$ Both these studies showed that rivaroxaban and dabigatran were not superior to aspirin in preventing stroke recurrence. In NAVIGATE-ESUS trial, rivaroxaban and aspirin had a comparable incidence of stroke recurrence ( $5.1 \%$ vs $4.8 \%, p=0.52$ ). Administration of rivaroxaban even increased the risk of major bleeding compared to aspirin $(1.8 \%$ vs $0.7 \%, \mathrm{p}<0.001) .^{7}$ The same result was also showed by RESPECT-ESUS trial. Dabigatran did have a lower incidence of stroke recurrence, however it was not significant compared to aspirin ( $4.1 \%$ vs $4.8 \%$, $\mathrm{p}=0.10)$. Dabigatran also increased the rsk of major bleeding $(1.7 \%)$ compared to aspirin $(1.4 \%) .{ }^{8}$ Patients with patent foramen ovale however might need a more invasive management strategy, a closure of patent foramen ovale using percutaneous or open technique. There has been several clinical trials about percutaneous closure of patent foramen ovale and its benefit in preventing stroke recurrence. These trials compared patent foramen ovale closure vs optimal medical therapy. The result of these studies are presented in Table 1 . While there are conflicting result, most of the studies reported that patent foramen ovale closure was beneficial than medical therapy alone in preventing stroke recurrence. ${ }^{31-36}$ The standard treatment for substenotic 
atherpsclerosis includes antiplatelet therapy, statin, and risk factor modification. Intervention management such as stenting or endarterectomy is not necessary in this group of patients unless, optimal medical therapy does not prevent the recurrence of stroke. ${ }^{24}$

\section{Discussion}

Cryptogenic stroke is still a challenge due its heterogenous concept and definition. While studies on cryptogenic stroke is still on going, stroke recurrence prevention strategy must be done based on current data. It is important to order a prolonged outpatient monitoring of cardiac rhythm instead of inpatient monitoring only. The optimal duration for heart rhythm monitoring is not known yet, but a longer duration are associated with increased detection of AF. However, it is recommended to monitor cardiac rhythm for at least 30 days. If no AF detected, a longer monitoring should be considered. ${ }^{37} \mathrm{~A}$ recent meta-analysis on optimal duration for prolonged cardiac monitoring also supported a longer term heart rhythm monitoring using implantable cardiac monitor (ICM) for patients with suspicion of cryptogenic stroke with initial negative result of AF. The result showed that longer term ICM duration ( $<6$ months, $\geq 6$ and $\leq 12$ months, $>12$ and $\leq 24$ months, > 34 months) was associated with an increased AF detection rates. ${ }^{38}$ While several recent studies on anticoagulant showed no significant benefit when compared to aspirin, the result from ongoing studies, ARCADIA and ATTICUS trial might give a clearer evidence for anticoagulant administration. ${ }^{39,40}$

\section{Conclusion}

Cryptogenic stroke is still a challenge and many studies have given more knowledge for us physician. The goal of cryptogenic stroke management is to prevent the stroke recurrence. Patients with suspicion of cryptogenic stroke must be evaluated thoroughly. A prolonged cardiac monitoring in the outpatient setting is recommended to increase AF detection. Other examination such as cardiac imaging are also important to determine any cardiac structure abnormalities, especially right-to-left shunt. This is important to decide whether invasive management is needed. Studies on management strategy are still underway for us to give a proper treatment. Management given to the patients aims to control the risk factor.

\section{Conflict of Interest}

None to be declared

\section{References}

1. Mozaffarian D, Benjamin EJ, Go AS, Arnett DK, Blaha MJ, Cushman M, et al. Heart Disease and Stroke Statistics-2016 Update: A Report From the American Heart Association. Circulation. 2016;133(4):e38-360.

2. Adams HP Jr, Bendixen BH, Kappelle LJ, Biller J, Love BB, Gordon DL, et al. Classification of subtype of acute ischemic stroke. Definitions for use in a multicenter clinical trial. TOAST. Trial of Org 10172 in Acute Stroke Treatment. Stroke. 1993;24(1):35-41

3. Arsava EM, Ballabio E, Benner T, Cole JW, DelgadoMartinez MP, Dichgans M, et al. The Causative Classification of Stroke system: an international reliability and optimization study. Neurology. 2010;75(14):1277-84.

4. Ay $\mathrm{H}$, Benner T, Arsava EM, Furie KL, Singhal $A B$, Jensen $M B$, et al. A computerized algorithm for etiologic classification of ischemic stroke: the Causative Classification of Stroke System. Stroke. 2007;38(11):2979-84.

5. Amarenco P, Bogousslavsky J, Caplan LR, Donnan GA, Wolf ME, Hennerici MG. The ASCOD phenotyping of ischemic stroke (Updated ASCO Phenotyping). Cerebrovasc Dis. 2013;36(1):1-5.

6. Hart RG, Diener HC, Coutts SB, Easton JD, Granger CB, O'Donnell MJ, et al. Embolic strokes of undetermined source: the case for a new clinical construct. Lancet Neurol. 2014;13(4):429-38.

7. Hart RG, Sharma M, Mundl H, Kasner SE, Bangdiwala SI, Berkowitz SD, et al. Rivaroxaban for Stroke Prevention after Embolic Stroke of Undetermined Source. N Engl J Med. 2018;378(23):2191-2201.

8. Diener HC, Sacco RL, Easton JD, Granger CB, Bernstein RA, Uchiyama $S$, et al. Dabigatran for Prevention of Stroke after Embolic Stroke of Undetermined Source. N Engl J Med. 2019;380(20):1906-1917. 
9. Li L, Yiin GS, Geraghty OC, Schulz UG, Kuker W, Mehta Z, et al. Incidence, outcome, risk factors, and long-term prognosis of cryptogenic transient ischaemic attack and ischaemic stroke: a populationbased study. Lancet Neurol. 2015;14(9):903-913.

10. Ji R, Schwamm LH, Pervez MA, Singhal AB. Ischemic stroke and transient ischemic attack in young adults: risk factors, diagnostic yield, neuroimaging, and thrombolysis. JAMA Neurol. 2013;70(1):51-7.

11. Wolf ME, Grittner U, Böttcher T, Norrving B, Rolfs A, Hennerici MG. Phenotypic ASCO Characterisation of Young Patients with Ischemic Stroke in the Prospective Multicentre Observational sifap1 Study. Cerebrovasc Dis. 2015;40(3-4):12935.

12. Putaala J, Metso AJ, Metso TM, Konkola N, Kraemer Y, Haapaniemi E, et al. Analysis of 1008 consecutive patients aged 15 to 49 with first-ever ischemic stroke: the Helsinki young stroke registry. Stroke. 2009;40(4):1195-203.

13. Gladstone DJ, Spring M, Dorian P, Panzov V, Thorpe KE, Hall J, et al. Atrial fibrillation in patients with cryptogenic stroke. N Engl J Med. 2014;370(26):2467-77.

14. Sanna T, Diener HC, Passman RS, Di Lazzaro V, Bernstein RA, Morillo CA, et al. Cryptogenic stroke and underlying atrial fibrillation. N Engl J Med. 2014;370(26):2478-86.

15. Jorfida M, Antolini M, Cerrato E, Caprioli MG, Castagno D, Garrone P, et al. Cryptogenic ischemic stroke and prevalence of asymptomatic atrial fibrillation: a prospective study. J Cardiovasc Med (Hagerstown). 2016;17(12):863-869.

16. Kottoor SJ, Arora RR. Cryptogenic Stroke: To Close a patent foramen ovale or Not to Close?. J Cent Nerv Syst Dis. 2018;10:1179573518819476.

17. Farb A, Ibrahim NG, Zuckerman BD. Patent foramen ovale after Cryptogenic Stroke - Assessing the Evidence for Closure. N Engl J Med. 2017 Sep 14;377(11):1006-1009.

18. Alsheikh-Ali AA, Thaler DE, Kent DM. patent foramen ovale in cryptogenic stroke: incidental or pathogenic? Stroke. 2009;40(7):2349-55.

19. Mojadidi MK, Winoker JS, Roberts SC, Msaouel P, Zaman MO, Gevorgyan R, et al. Accuracy of conventional transthoracic echocardiography for the diagnosis of intracardiac right-to-left shunt: a metaanalysis of prospective studies. Echocardiography. 2014;31(9):1036-48.

20. Singh HS, Katchi F, Naidu SS. patent foramen ovale Closure for Cryptogenic Stroke: A Review and Clinical Treatment Algorithm. Cardiol Rev. 2017;25(4):147-157.

21. Tobe J, Bogiatzi C, Munoz C, Tamayo A, Spence JD. Transcranial Doppler is Complementary to Echocardiography for Detection and Risk Stratification of patent foramen ovale. Can J Cardiol. 2016;32(8):986.e9-986.e16.

22. Kent DM, Ruthazer R, Weimar C, Mas JL, Serena J, Homma $S$, et al. An index to identify stroke-related vs incidental patent foramen ovale in cryptogenic stroke. Neurology. 2013;81(7):619-25.

23. Gladstone DJ, Dorian P, Spring M, Panzov V, Mamdani M, Healey JS, et al. Atrial premature beats predict atrial fibrillation in cryptogenic stroke: results from the EMBRACE trial. Stroke. 2015;46(4):936-41.

24. Mac Grory B, Flood SP, Apostolidou E, Yaghi S. Cryptogenic Stroke: Diagnostic Workup and Management. Curr Treat Options Cardiovasc Med. 2019 Dec 3;21(11):77.

25. Fonseca AC, Alves P, Inácio N, Marto JP, VianaBaptista M, Pinho-E-Melo T, et al. Patients With Undetermined Stroke Have Increased Atrial Fibrosis: A Cardiac Magnetic Resonance Imaging Study. Stroke. 2018;49(3):734-737.

26. Gupta A, Gialdini G, Lerario MP, Baradaran H, Giambrone A, Navi BB, et al. Magnetic resonance angiography detection of abnormal carotid artery plaque in patients with cryptogenic stroke. J Am Heart Assoc. 2015;4(6):e002012.

27. Kernan WN, Ovbiagele B, Black HR, Bravata DM, Chimowitz MI, Ezekowitz MD, et al. Guidelines for the prevention of stroke in patients with stroke and transient ischemic attack: a guideline for healthcare professionals from the American Heart Association/American Stroke Association. Stroke. 2014;45(7):2160-236.

28. Molina CA, Santamarina E, Alvarez-Sabín J. Cryptogenic stroke, aortic arch atheroma and patent foramen ovale. Cerebrovasc Dis. 2007;24 Suppl 1:84-8. 
29. Ito A, Sugioka K, Matsumura Y, Fujita S, Iwata S, Hanatani A, et al. Rapid and accurate assessment of aortic arch atherosclerosis using simultaneous multiplane imaging by transesophageal echocardiography. Ultrasound Med Biol. 2013;39(8):1337-42.

30. Nouh A, Hussain M, Mehta T, Yaghi S. Embolic Strokes of Unknown Source and Cryptogenic Stroke: Implications in Clinical Practice. Front Neurol. 2016;7:37.

31. Furlan AJ, Reisman M, Massaro J, Mauri L, Adams $\mathrm{H}$, Albers GW, et al. Closure or medical therapy for cryptogenic stroke with patent foramen ovale. $\mathrm{N}$ Engl J Med. 2012;366(11):991-9.

32. Meier B, Kalesan B, Mattle HP, Khattab AA, Hildick-Smith D, Dudek D, et al. Percutaneous closure of patent foramen ovale in cryptogenic embolism. N Engl J Med. 2013;368(12):1083-91.

33. Søndergaard L, Kasner SE, Rhodes JF, Andersen $\mathrm{G}$, Iversen $\mathrm{HK}$, Nielsen-Kudsk JE, et al. patent foramen ovale Closure or Antiplatelet Therapy for Cryptogenic Stroke. N Engl J Med. 2017;377(11):1033-1042.

34. Saver JL, Carroll JD, Thaler DE, Smalling RW, MacDonald LA, Marks DS, et al. Long-Term Outcomes of patent foramen ovale Closure or Medical Therapy after Stroke. N Engl J Med. 2017;377(11):1022-1032.

35. Mas JL, Derumeaux G, Guillon B, Massardier E, Hosseini $\mathrm{H}$, Mechtouff L, et al. patent foramen ovale Closure or Anticoagulation vs. Antiplatelets after Stroke. N Engl J Med. 2017;377(11):10111021.

36. Lee PH, Song JK, Kim JS, Heo R, Lee S, Kim DH, et al. Cryptogenic stroke and high-risk patent foramen ovale: the DEFENSE-patent foramen ovale trial. J Am Coll Cardiol. 2018;71(20):2335-42

37. Albers GW, Bernstein RA, Brachmann J, Camm J, Easton JD, Fromm P, et al. Heart Rhythm Monitoring Strategies for Cryptogenic Stroke: 2015 Diagnostics and Monitoring Stroke Focus Group Report. J Am Heart Assoc. 2016;5(3):e002944.

38. Tsivgoulis G, Katsanos AH, Köhrmann M, Caso V, Perren F, Palaiodimou L, et al. Duration of Implantable Cardiac Monitoring and Detection of Atrial Fibrillation in Ischemic Stroke Patients: A Systematic Review and Meta-Analysis. J Stroke. 2019;21(3):302-311.
39. Kamel H, Longstreth WT Jr, Tirschwell DL, Kronmal RA, Broderick JP, Palesch YY, et al. The AtRial Cardiopathy and Antithrombotic Drugs In prevention After cryptogenic stroke randomized trial: Rationale and methods. Int J Stroke. 2019;14(2):207-214

40. Geisler T, Poli S, Meisner C, Schreieck J, Zuern CS, Nägele T, et al. Apixaban for treatment of embolic stroke of undetermined source (ATTICUS randomized trial): Rationale and study design. Int J Stroke. 2017;12(9):985-990. 